\title{
The Mechanical Design of an Adjustable Baby Carriage I Walker Based on Human Factors Engineering
}

\author{
Yumei Bao ${ }^{1, a}$, Weichao Cheng ${ }^{1, b}$, Hao Chai ${ }^{1, c}$, Jun Lv ${ }^{1,2, d}$, Guozhong Chai ${ }^{1, e}$ \\ ${ }^{1}$ Key Laboratory of E\&M (Zhejiang University of Technology), Ministry of Education \& Zhejiang \\ Province \\ ${ }^{2}$ Yiwu Industrial \&Commercial College \\ abaoym@zjut.edu.cn, b15757175024@163.com, 'chaih1985@163.com

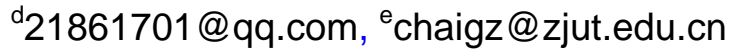

Keywords: Multifunctional baby carriage, Human factors engineering, Mechanical design

\begin{abstract}
Based on the principle of human factors engineering, the relevant data of the users including the babies and the caregivers are analyzed to provide parameters for mechanical structural design. The designed adjustable baby carriage/walker features novel multifunctional and is suitable for the babies in their different months.
\end{abstract}

\section{Introduction}

There are 77 million babies ( $0 \sim 4$ years old) in China in 2013, and the value increases by 10 - 20 million babies per year, so the peak value will be about 200 million babies by the year 2020 [1]. People pay more and more attention to the growth of the baby. But the baby products market in China is still in its infancy and has a huge potential.

Baby carriages are ubiquitous and intended to provide a safe and secure means to transport children and are regularly used by caregivers. While baby walkers are used to help babies to walk. All these baby mechanical products must meet the operator's requirements and feature simple and easy operation, considering not only the original mechanical structure, but also a baby- comfortable environment.

In what follows an adjustable baby carriage/walker is developed for the baby of different height in their different months by adjusting the seat space size manually, converting between seat, couch and walker.

\section{Human Factors Engineering principles}

Human factor plays a significant role in all stages of industrial processes. Human factors engineering /Ergonomics is the primary discipline that considers the human element in engineering systems through taking human needs, abilities and limitations into consideration. The domain utilizes knowledge and expertise gained from a wide-range of disciplines to design and evaluate products, services, tasks, processes, environments and systems [2].

A new type of adjustable baby carriage should obey the following principles:

1. The size of the seat must match with the size of the baby's body;

2. The design of the baby carriage must be able to provide users with a stable and safe environment (stability and safety);

3. The overall height of the baby carriage must adapt to the requirements of the caregivers.

Basic data. The users are infants and young children less than 18 months of age, who have no concept about appliances and toys. Therefore, we should take the safety and comfort into consideration mainly. The height, weight and chest data of $0 \sim 18$ months baby (including boy and girl) are shown in table $1[3,4]$. 
Table 1 The height, weight and chest data of baby boy / girl [3.4]

\begin{tabular}{ccccccc}
\hline $\begin{array}{c}\text { Baby's } \\
\text { age(month) }\end{array}$ & $\begin{array}{c}\text { Baby boy's } \\
\text { weight }(\mathrm{kg})\end{array}$ & $\begin{array}{c}\text { Baby boy's } \\
\text { height }(\mathrm{cm})\end{array}$ & $\begin{array}{c}\text { Baby } \\
\text { boy's } \\
\text { chest }(\mathrm{cm})\end{array}$ & $\begin{array}{c}\text { Baby girl's } \\
\text { weight }(\mathrm{kg})\end{array}$ & $\begin{array}{c}\text { Baby girl's } \\
\text { height }(\mathrm{cm})\end{array}$ & $\begin{array}{c}\text { Baby } \\
\text { girl's } \\
\text { chest }(\mathrm{cm})\end{array}$ \\
\hline & $2.9 \sim 3.8$ & $48.2 \sim 52.8$ & 32.8 & $2.7 \sim 3.6$ & $47.7 \sim 52.0$ & 32.6 \\
1 & $3.6 \sim 5.0$ & $52.1 \sim 57.0$ & 37.9 & $3.4 \sim 4.5$ & $51.2 \sim 55.8$ & 36.9 \\
2 & $4.3 \sim 6.0$ & $55.5 \sim 60.7$ & 40.0 & $4.0 \sim 5.4$ & $54.4 \sim 59.2$ & 38.9 \\
3 & $5.0 \sim 6.9$ & $58.5 \sim 63.7$ & 41.3 & $4.7 \sim 6.2$ & $57.1 \sim 59.5$ & 40.3 \\
4 & $5.7 \sim 7.6$ & $61.0 \sim 66.4$ & 42.3 & $5.3 \sim 6.9$ & $59.4 \sim 64.5$ & 41.1 \\
5 & $6.3 \sim 8.2$ & $63.2 \sim 68.6$ & 42.9 & $5.8 \sim 7.5$ & $61.5 \sim 66.7$ & 41.9 \\
6 & $6.9 \sim 8.8$ & $65.1 \sim 70.5$ & 43.8 & $6.3 \sim 8.1$ & $63.3 \sim 68.6$ & 42.7 \\
8 & $7.8 \sim 9.8$ & $68.3 \sim 73.6$ & 44.7 & $7.2 \sim 9.1$ & $66.4 \sim 71.8$ & 43.4 \\
10 & $8.6 \sim 10.6$ & $71.0 \sim 76.3$ & 45.4 & $7.9 \sim 9.9$ & $69.0 \sim 74.5$ & 44.2 \\
12 & $9.1 \sim 11.3$ & $73.4 \sim 78.8$ & 46.1 & $8.5 \sim 10.6$ & $71.5 \sim 77.1$ & 45.0 \\
18 & $10.3 \sim 12.7$ & $79.4 \sim 85.4$ & 47.6 & $9.7 \sim 12.0$ & $77.9 \sim 84.0$ & 46.6 \\
\hline
\end{tabular}

The baby is the dominant user of the baby carriage, and the potential user (operator) is an adult (a caregiver). Based on GB 10000-88[5], the basic human body size data including height, upper arm length, forearm length, and finger length of 18 to 60 year old adult men and women are shown in table 2.

Table 2 Some sizes of 18-60 years old male / female body ( $\mathrm{mm})$ [5]

\begin{tabular}{ccccccccccccccccc}
\hline Age groups & \multicolumn{1}{c}{ Male } & $(18 \sim 60$ years old $)$ & \multicolumn{1}{c}{ Female $(18 \sim 55$ years old $)$} \\
\hline $\begin{array}{c}\text { peccentages } \\
\text { Measurentexts }\end{array}$ & 1 & 5 & 10 & 50 & 90 & 95 & 99 & 1 & 5 & 10 & 50 & 90 & 95 & 99 \\
\hline Height & 1543 & 1583 & 1604 & 1678 & 1754 & 1775 & 1814 & 1449 & 1484 & 1503 & 1570 & 1640 & 1679 & 1697 \\
Upper arm length & 279 & 289 & 294 & 313 & 333 & 338 & 349 & 252 & 262 & 267 & 284 & 301 & 306 & 319 \\
Forearm length & 206 & 213 & 220 & 237 & 253 & 258 & 268 & 185 & 193 & 198 & 213 & 229 & 234 & 242 \\
Index finger length & 60 & 63 & 64 & 69 & 74 & 76 & 79 & 57 & 60 & 61 & 66 & 71 & 72 & 76 \\
\hline
\end{tabular}

The choice of color. Reasonable color can not only stimulate the senses, add visual effects, but also improve efficiency in the use of the product. Children's aesthetic psychology is in its infancy, they begin to understand the color in this period, the investigation showed that children master the color in order of yellow, red, green, blue, purple, orange. Therefore, the color of the baby carriage can use light colors or three primary colors, such as: red, yellow, blue owing to its simple, clear, and easy for the baby to identify. Appropriate color stimulation is of great help on infant mental development, but too many red and green colors may cause visual fatigue.

\section{Computer aided design of the mechanical structure}

The choice of material. Considering its good processing performance and mechanical properties, the main support frame of the baby carriage is aluminum alloy 6061. The material of the connecting parts is 45 steel because of its high strength. The material of seat and back is polyvinyl chloride (PVC). Taking the comfort of the operator into account, some soft materials such as rubber are wrapped on the stroller handle.

The baby carriage is designed for the babies in their age of less than 18 months. The main functions are couch, seat and walker. The schematic diagram of the baby carriage is shown in Fig.1. 


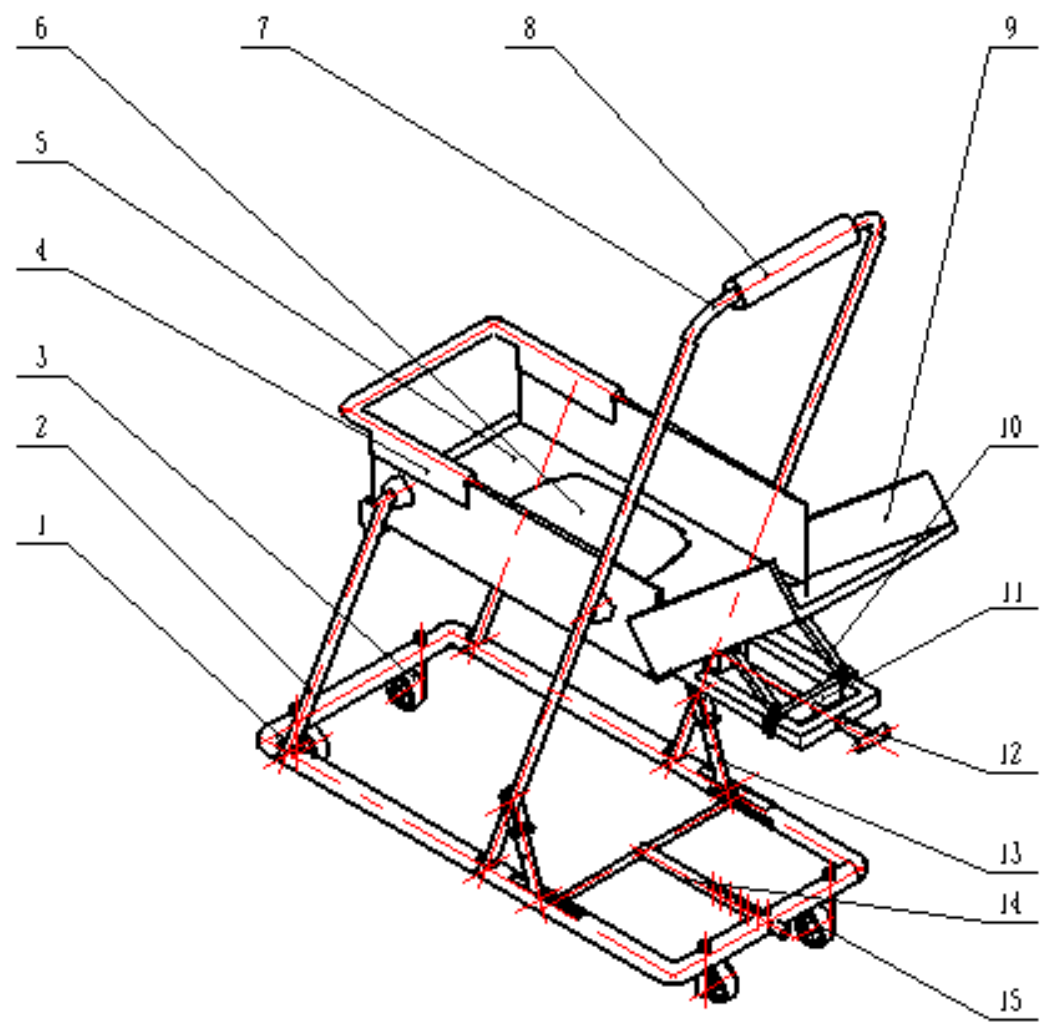

Fig1. Schematic diagram of the baby carriage

1-base; 2- forelimb; 3 -front wheel; 4- guardrail; 5- seat; 6- seat plate; 7- hind limb; 8- handrail; 9- seat back; 10supporting rod 1; 11- slider ; 12- handle; 13- supporting rod 2; 14- connecting rod; 15- back wheel

Chair lifting mechanism. A slider-crank mechanism is applied as lifting mechanism to convert the straight line motion into the rotary motion as shown in Fig. 2, in which the component 1 is the hind legs of the baby carriage, 2 is the support seat of the hind legs, and 3 is the connecting rod. By moving the connecting rod 3 , the caregivers can adjust the carriage legs.

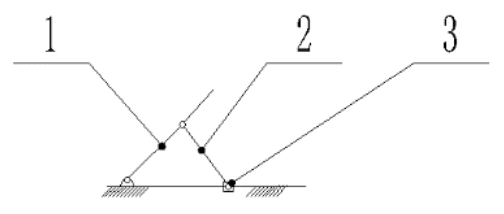

slider-crank mechanism

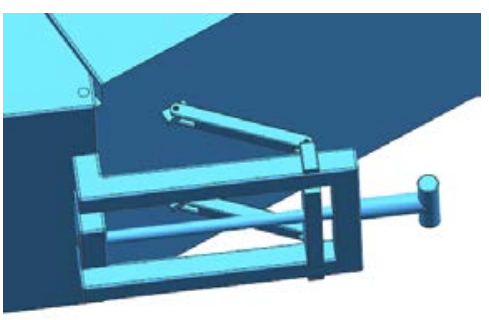

3D diagram

Fig.2 Chair lifting mechanism

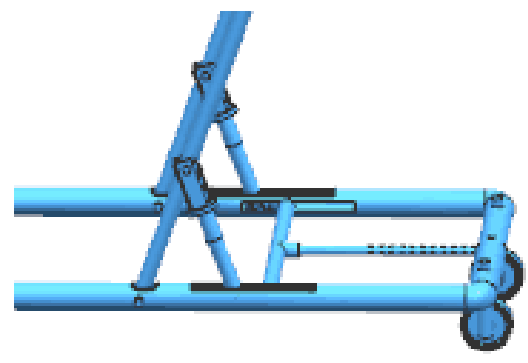

Fig.3 Seat rotating mechanism

Seat rotating mechanism. The selected seat rotating mechanism (Fig.3) is similar to the chair lifting mechanism. The horizontal movement of the slider is accomplished by a screw thread and the chair angle is locked by the self-lock of the screw thread.

Three layouts of the baby carriage (as shown in Fig.4-6). 


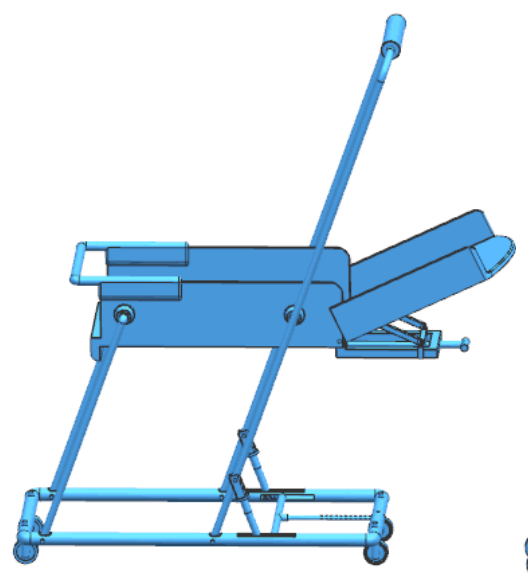

Fig.4 The couch

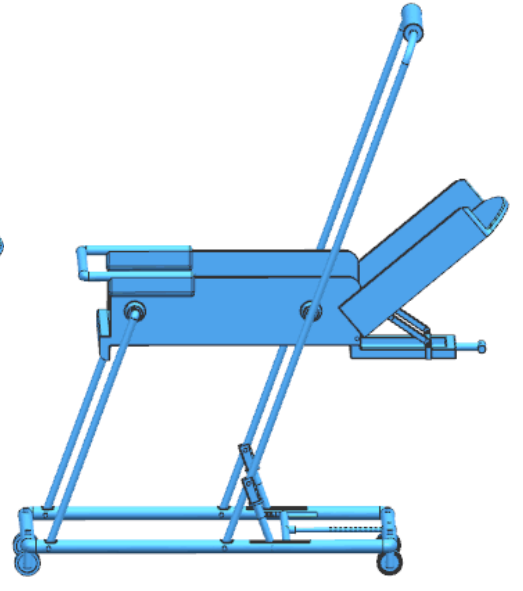

Fig.5 The seat

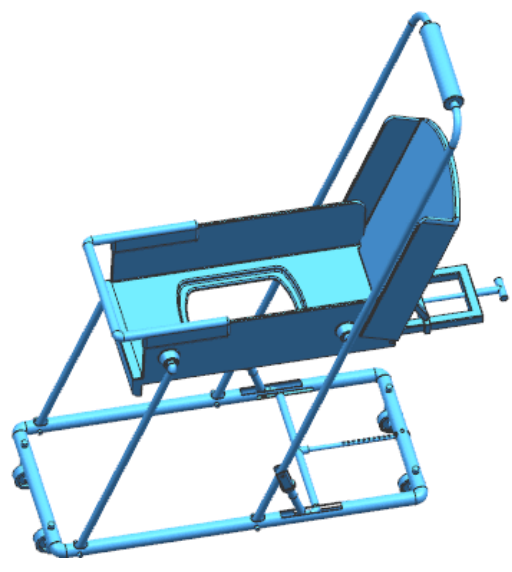

Fig.6 The walker

a) Couch. When the angle between seat back and horizontal plane is smaller than 30degrees, it is in the layout of the couch, as shown in Fig.4.

b) Seat. When the angle between seat back and horizontal plane is larger than 30 degrees, it is in the layout of the seat, as shown in Fig.5.

c) Walker. After the seat plate in the middle of the seat is removed through a threaded connection, and installing a purchased walker seats (omitted in the diagram), the carriage becomes a baby walker. And the caregivers can move the rod to adjust the seat height, so as to make it adapt to different heights of babies, as shown in Fig.6.

\section{Conclusions}

A new multi-functional baby carriage (couch or seat)/walker is designed based on the human factors engineering with the analysis of the relevant data of the users (including the babies and the caregivers). The slider-crank mechanism is selected to adjust the seat height and the angles.

\section{References}

[1] CHINA POPULATION STATISTICS YEARBOOK , http://www.stats.gov.cn/tjsj/ndsj/

[2] H. Onan Demirel, Le Zhang, Vincent G. Duffy. (2016). Opportunities for meeting sustainability objectives. International Journal of Industrial Ergonomics, 51:73-81.

[3] Information on http:/ /baobao.sohu.com/20150117/n407866409.shtml u1ZaHOQ4Wg39Hrc_pCh1k8BDqlqlD6c0nqtzZed1GWR3T0VFBmAIeKorQx7

[5] GB 10000-88. (1988). Human dimensions of Chinese adults 